\title{
Increased Myogenic and Protein Turnover Signaling in Skeletal Muscle of Chronic Obstructive Pulmonary Disease Patients With Sarcopenia
}

Citation for published version (APA):

Kneppers, A. E. M., Langen, R. C. J., Gosker, H. R., Verdijk, L. B., Lipovec, N. C., Leermakers, P. A., Kelders, M. C. J. M., de Theije, C. C., Omersa, D., Lainscak, M., \& Schols, A. M. W. J. (2017). Increased Myogenic and Protein Turnover Signaling in Skeletal Muscle of Chronic Obstructive Pulmonary Disease Patients With Sarcopenia. Journal of the American Medical Directors Association, 18(7), 637.e1-637.e11. https://doi.org/10.1016/j.jamda.2017.04.016

Document status and date:

Published: 01/07/2017

DOI:

10.1016/j.jamda.2017.04.016

Document Version:

Publisher's PDF, also known as Version of record

Document license:

Taverne

Please check the document version of this publication:

- A submitted manuscript is the version of the article upon submission and before peer-review. There can be important differences between the submitted version and the official published version of record.

People interested in the research are advised to contact the author for the final version of the publication, or visit the DOI to the publisher's website.

- The final author version and the galley proof are versions of the publication after peer review.

- The final published version features the final layout of the paper including the volume, issue and page numbers.

Link to publication

\footnotetext{
General rights rights.

- You may freely distribute the URL identifying the publication in the public portal. please follow below link for the End User Agreement:

www.umlib.nl/taverne-license

Take down policy

If you believe that this document breaches copyright please contact us at:

repository@maastrichtuniversity.nl

providing details and we will investigate your claim.
}

Copyright and moral rights for the publications made accessible in the public portal are retained by the authors and/or other copyright owners and it is a condition of accessing publications that users recognise and abide by the legal requirements associated with these

- Users may download and print one copy of any publication from the public portal for the purpose of private study or research.

- You may not further distribute the material or use it for any profit-making activity or commercial gain

If the publication is distributed under the terms of Article $25 \mathrm{fa}$ of the Dutch Copyright Act, indicated by the "Taverne" license above, 
Original Study

\title{
Increased Myogenic and Protein Turnover Signaling in Skeletal Muscle of Chronic Obstructive Pulmonary Disease Patients With Sarcopenia
}

\author{
Anita E.M. Kneppers MSc ${ }^{\mathrm{a}}$, Ramon C.J. Langen $\mathrm{PhD}^{\mathrm{a}}$, Harry R. Gosker $\mathrm{PhD}^{\mathrm{a}}$, \\ Lex B. Verdijk PhD ${ }^{b}$, Nanca Cebron Lipovec PhD ${ }^{c}$, Pieter A. Leermakers MSc ${ }^{a}$, \\ Marco C.J.M. Kelders BSc ${ }^{\mathrm{a}}$, Chiel C. de Theije PhD ${ }^{\mathrm{a}}$, Daniel Omersa MD ${ }^{\mathrm{d}}$, \\ Mitja Lainscak PhD ${ }^{\mathrm{e}, \mathrm{f}}$, Annemie M.W.J. Schols PhD ${ }^{\mathrm{a}, *}$

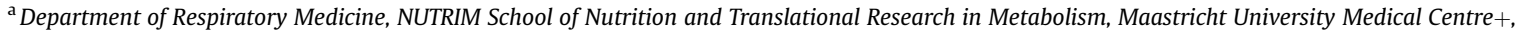 \\ Maastricht, the Netherlands \\ ${ }^{\mathrm{b}}$ Department of Human Biology and Movement Sciences, NUTRIM School of Nutrition and Translational Research in Metabolism, Maastricht University \\ Medical Centre+, Maastricht, the Netherlands \\ ${ }^{\mathrm{c}}$ Pharmacy Department, University Clinic of Pulmonary and Allergic Diseases Golnik, Golnik, Slovenia \\ ${ }^{\mathrm{d}}$ Research Department, National Institute of Public Health, Ljubljana, Slovenia \\ e Department of Cardiology, General Hospital Celje, Celje, Slovenia \\ ${ }^{\mathrm{f}}$ Faculty of Medicine, University of Ljubljana, Ljubljana, Slovenia
}

\section{Keywords:}

Muscular atrophy

protein biosynthesis

proteolysis

myogenic differentiation

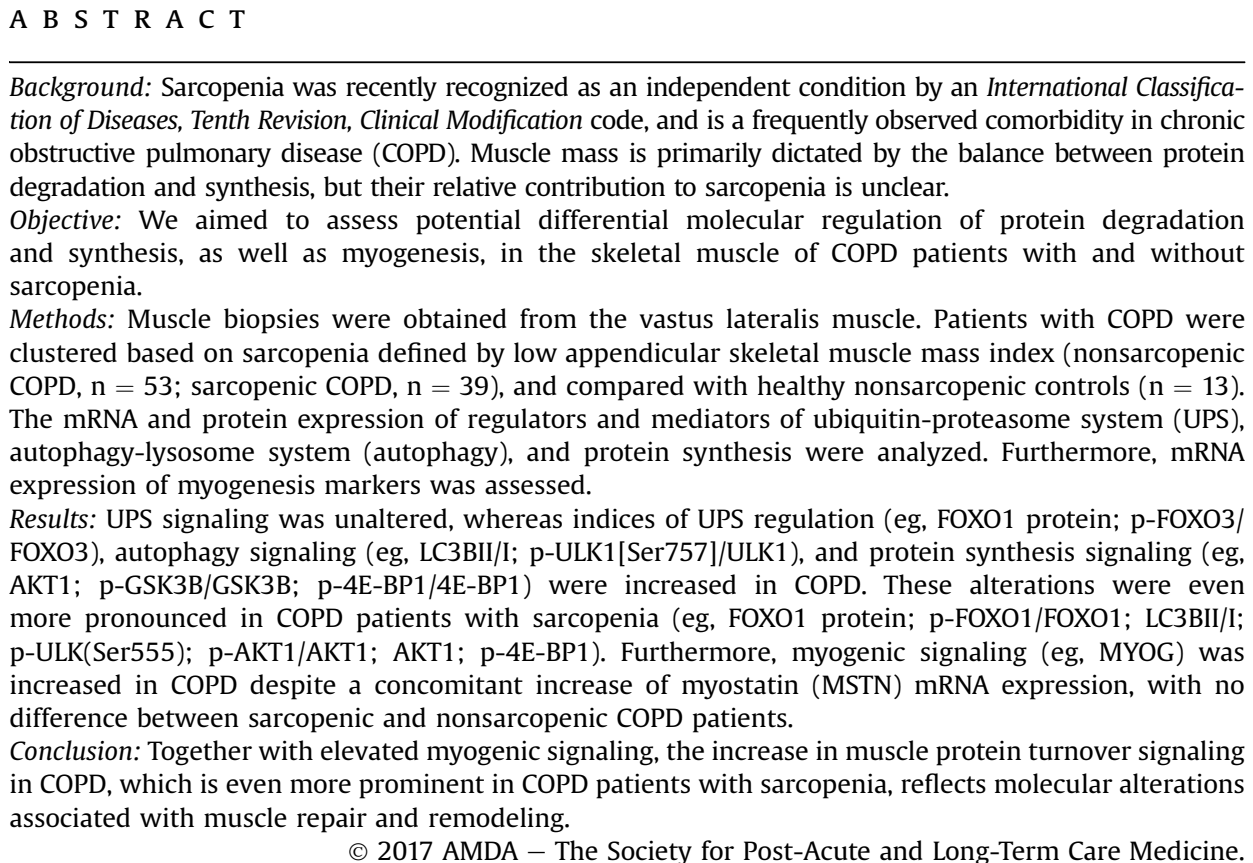

M.L. and A.M.S. contributed equally to this article

The authors declare no conflicts of interest.

* Address correspondence to Annemie M.W.J. Schols, PhD, Department of Respiratory Medicine, NUTRIM School of Nutrition and Translational Research in
Metabolism, Maastricht University Medical Centre+, PO Box 5800, Maastricht 6202 AZ, the Netherlands.

E-mail address: a.schols@maastrichtuniversity.nl (A.M.W.J. Schols). 
Sarcopenia is defined as the loss of function in the presence of loss of muscle mass, and was recently recognized as an independent condition by an International Classification of Diseases, Tenth Revision, Clinical Modification code. ${ }^{1}$ Apart from an age-associated decline in muscle mass, sarcopenia also encompasses the loss of muscle mass due to diseases such as chronic obstructive pulmonary disease (COPD) ${ }^{2}$ In COPD patients, sarcopenia is a frequently observed comorbidity, affecting exercise capacity, ${ }^{3,4}$ quality of life, ${ }^{3}$ and survival. ${ }^{5-7}$ Although muscle mass maintenance is considered to be primarily dictated by the balance between protein degradation and protein synthesis rates (ie, protein turnover), their relative contribution to imbalanced protein turnover during muscle mass loss remains unclear.

To provide a first insight into the potential drivers of this imbalance between muscle protein synthesis and breakdown in COPD patients, several studies assessed the molecular regulation of skeletal muscle protein turnover in COPD, and nearly all point to both increased protein degradation signaling ${ }^{8-14}$ and increased protein synthesis signaling. ${ }^{10,11,15}$ These findings are in accordance with the reported increase in whole body protein turnover rate in COPD as assessed by stable isotopes. ${ }^{16}$ It was previously suggested that increased protein synthesis signaling in COPD may serve to maintain muscle mass in the presence of an elevated protein degradation rate. ${ }^{11}$ However, such a compensatory mechanism to prevent muscle atrophy appears insufficient, because the prevalence of sarcopenia in COPD patients is high (ie, $12 \%-33 \%){ }^{17-19}$ Although there are some data available on protein turnover signaling in sarcopenic COPD patients, ${ }^{8,9,11}$ these studies are either limited in sample size or focus solely on either protein degradation or protein synthesis signaling. Furthermore, the role of myogenesis in muscle mass maintenance is frequently overlooked or incompletely assessed.

A comprehensive analysis of myogenic and protein turnover regulation in COPD patients with and without sarcopenia would provide further insight into the underlying skeletal muscle pathology, potentially providing new targets for intervention. In the present study, we therefore aimed to assess potential differential regulation of protein degradation and synthesis, as well as myogenesis, through analysis of an extensive panel of molecular regulators and mediators of myogenic and protein turnover signaling in the skeletal muscle of COPD patients with and without sarcopenia compared with healthy controls.

\section{Materials and Methods}

\section{Study Design and Participants}

The skeletal muscle molecular profiles of patients from 2 prospective cohort studies were analyzed. The study performed in Maastricht was registered at www.trialregister.nl as NTR1402, written informed consent was obtained from all participants, and the study was approved by the Maastricht University Medical Centre+ (Maastricht, the Netherlands) ethical review board (08-2-059). The study design was previously published. ${ }^{20}$ The study performed in Golnik was registered at www.clinicaltrials.gov as NCT02550808, written informed consent was obtained from all participants, and the study was approved by the Slovenian National Medical Ethics Committee (Ljubljana, Slovenia). The study design was previously published. ${ }^{21}$ Only data from baseline (ie, before pulmonary rehabilitation) measurements were used in the current study. All included patients were in a stable disease state, free from exacerbations in the 4 weeks before start of the study protocol.

Participants were excluded from the current analysis if the muscle biopsy or appendicular skeletal muscle mass index (ASMI) measurement was missing. Sarcopenia was solely defined according to cutoffs for ASMI $\left(<7.23 \mathrm{~kg} / \mathrm{m}^{2} \text { for men; }<5.76 \mathrm{~kg} / \mathrm{m}^{2} \text { for women }\right)^{22}$; see Figure 1. One participant without COPD was classified as sarcopenic and was therefore excluded from the analyses, yielding a study population of 13 healthy controls and 92 COPD patients.

\section{Pulmonary and Physical Function}

Spirometry was used to obtain forced expiratory volume in $1 \mathrm{sec}$ ond $\left(\mathrm{FEV}_{1}\right)$, forced vital capacity $(\mathrm{FVC})$, and their ratio $\left(\mathrm{FEV}_{1} / \mathrm{FVC}\right)$ according to the European Respiratory Society guidelines. ${ }^{23}$ Patients were classified by disease severity based on Global Initiative for Chronic Obstructive Lung Disease (GOLD) stage. ${ }^{24}$ Physical function was assessed by peak load, determined by an incremental load cycling test as previously described. ${ }^{25}$

\section{Anthropometry and Body Composition}

Body mass index (BMI) was calculated as body mass $/$ height ${ }^{2}\left(\mathrm{~kg} / \mathrm{m}^{2}\right)$. Whole body dual-energy x-ray absorptiometry (Hologic QDR Series Explorer bone densitometer; Hologic Inc, Marlborough, MA) was used to assess total and appendicular (ie, arms and legs) fat mass and fat-free mass. Fat-Free Mass Index (FFMI) was calculated as fat-free mass/ height ${ }^{2}\left(\mathrm{~kg} / \mathrm{m}^{2}\right)$. ASMI was calculated as appendicular skeletal muscle mass/height ${ }^{2}\left(\mathrm{~kg} / \mathrm{m}^{2}\right)$.

\section{Muscle Biopsy and Analyses}

Biopsies were obtained from the vastus lateralis muscle of the dominant leg by needle biopsy, at least 20 hours after the last exercise test. Muscle tissue was snap-frozen in liquid nitrogen, and stored at $-80^{\circ} \mathrm{C}$. Tissue processing and molecular analyses were performed collectively.

\section{Reverse Transcriptase-Quantitative Polymerase Chain Reaction and Western Blotting}

Molecular analyses were performed in biopsies from all participants. After removal of technical outliers, which varied between different analyses, the total sample size for protein and mRNA targets included 10 to 13 controls, 50 to 53 nonsarcopenic patients with COPD, and 38 to 39 sarcopenic COPD patients.

Details on the procedures and the exact sample size per analyzed target are provided in the supplementary methods.

\section{Statistics}

Differences among nonsarcopenic patients with COPD, sarcopenic patients with COPD, and controls were tested by 1-way analysis of variance with Bonferroni post hoc comparisons in case of a significant group effect. Furthermore, differences between patients with COPD and controls were tested using independent $t$ test. Relevant results of this comparison are presented in the figures. Analyses were performed using SPSS Statistics (version 22.0; IBM Corp, Armonk, NY). A P value less than .05 was considered statistically significant.

\section{Results}

\section{Participant Characteristics}

Based on gender-specific cutoffs for ASMI, ${ }^{22} 39$ COPD patients (42\%) were sarcopenic, whereas 53 COPD patients (58\%) and all control participants were nonsarcopenic. Patient characteristics are presented in Table 1 . Although the sarcopenic COPD group contained slightly more men, groups did not differ significantly in sex distribution and age. BMI was lower in sarcopenic than in nonsarcopenic COPD patients, but controls did not differ from either COPD subgroup. Besides ASMI, FFMI was lower in sarcopenic COPD patients than in nonsarcopenic COPD 


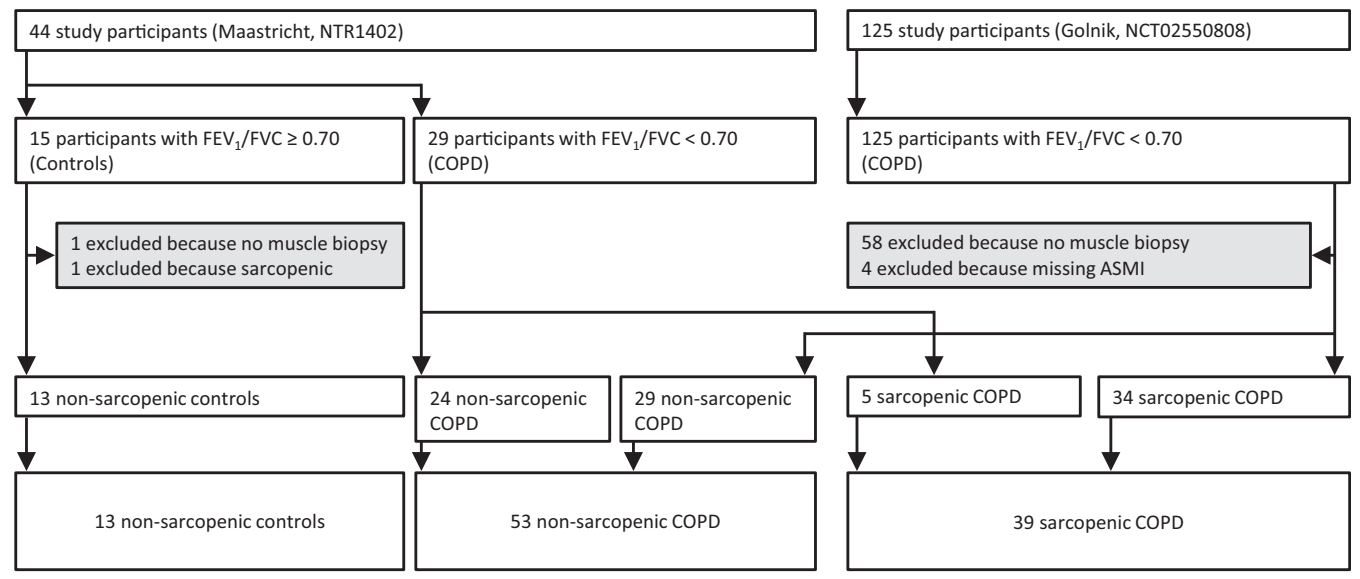

Fig. 1. Flow chart of participant selection and clustering. Sarcopenia: ASMI $<7.23 \mathrm{~kg} / \mathrm{m}^{2}$ for men; $<5.67 \mathrm{~kg} / \mathrm{m}^{2}$ for women. ${ }^{22}$

patients and controls. Furthermore, physical function was decreased in COPD patients compared with controls, and tended to be even further decreased in sarcopenic COPD patients compared with nonsarcopenic COPD patients. $\mathrm{FEV}_{1} / \mathrm{FVC}$ ratio and $\mathrm{FEV}_{1}$ (\% predicted) were lower in COPD patients than in controls, and $\mathrm{FEV}_{1}$ (\% predicted) was even lower in sarcopenic than in nonsarcopenic COPD patients. Correspondingly, nonsarcopenic COPD patients most often had moderate (32\%) to severe (45\%) COPD, whereas sarcopenic COPD patients most often had severe (56\%) to very severe (31\%) COPD based on GOLD stage. Together, this shows that lung function is more impaired in sarcopenic than in nonsarcopenic COPD patients.

\section{Protein Degradation Signaling}

To assess potential differential regulation of skeletal muscle protein degradation signaling in COPD and sarcopenic COPD, markers of

Table 1

General Characteristics

\begin{tabular}{|c|c|c|c|c|}
\hline & $\begin{array}{l}\text { Control, } \\
\mathrm{n}=13\end{array}$ & $\begin{array}{l}\text { COPD, No } \\
\text { Sarcopenia, } \\
\mathrm{n}=53\end{array}$ & $\begin{array}{l}\text { COPD, } \\
\text { Sarcopenia, } \\
\mathrm{n}=39\end{array}$ & $\begin{array}{l}\text { Overall } \\
P \text { Value }\end{array}$ \\
\hline \multicolumn{5}{|l|}{ Demographics } \\
\hline Age, $y$ & $64.5 \pm 5.4$ & $64.0 \pm 7.4$ & $66.4 \pm 8.4$ & NS \\
\hline Sex, \% male & 53.8 & 60.4 & 74.4 & NS \\
\hline \multicolumn{5}{|l|}{ Body composition } \\
\hline BMI, $\mathrm{kg} / \mathrm{cm}^{2}$ & $24.8 \pm 3.4$ & $26.7 \pm 4.0$ & $22.9 \pm 2.8^{\ddagger \dagger \ddagger}$ & $<.001$ \\
\hline ASMI, $\mathrm{kg} / \mathrm{cm}^{2}$ & $7.48 \pm 1.01$ & $7.42 \pm 1.01$ & $6.03 \pm 0.85^{* * / t \ddagger \ddagger}$ & $<.001$ \\
\hline Female & $6.52 \pm 0.49$ & $6.43 \pm 0.61$ & $4.98 \pm 0.48^{* * / t \ddagger \ddagger}$ & $<.001$ \\
\hline Male & $8.31 \pm 0.37$ & $8.06 \pm 0.64$ & $6.39 \pm 0.61^{* * / t \ddagger \ddagger}$ & $<.001$ \\
\hline FFMI, $\mathrm{kg} / \mathrm{cm}^{2}$ & $17.9 \pm 1.9$ & $18.0 \pm 2.5$ & $15.9 \pm 2.4^{* / \neq \ddagger \ddagger}$ & $<.001$ \\
\hline Female & $16.3 \pm 1.4$ & $15.9 \pm 1.3$ & $13.1 \pm 1.1^{* * / \ddagger \ddagger \ddagger}$ & $<.001$ \\
\hline Male & $19.2 \pm 1.0$ & $19.5 \pm 2.0$ & $16.8 \pm 1.9^{* / \ddagger \ddagger \ddagger}$ & $<.001$ \\
\hline \multicolumn{5}{|l|}{ Physical function } \\
\hline Peak load, Watt & $190.3 \pm 62.8$ & $73.4 \pm 24.4^{* *}$ & $58.1 \pm 24.9^{* * / \dagger}$ & $<.001$ \\
\hline Female & $136.0 \pm 6.3$ & $65.5 \pm 19.2^{* *}$ & $47.0 \pm 19.5^{* * / \ddagger}$ & $<.001$ \\
\hline Male & $236.9 \pm 48.9$ & $78.1 \pm 26.1^{* *}$ & $62.3 \pm 25.7^{* *}$ & $<.001$ \\
\hline \multicolumn{5}{|l|}{ Lung function } \\
\hline $\mathrm{FEV}_{1}, \%$ predicted & $113.5 \pm 12.9$ & $48.6 \pm 18.3^{* *}$ & $36.4 \pm 12.9^{* * / \ddagger \ddagger}$ & $<.001$ \\
\hline $\mathrm{FEV}_{1} / \mathrm{FVC}, \%$ & $73.1 \pm 4.9$ & $39.5 \pm 12.2^{* *}$ & $34.5 \pm 9.8^{* * / \dagger}$ & $<.001$ \\
\hline GOLD, $\%$ & & & & $<.05$ \\
\hline 1 & & 6 & 0 & \\
\hline 2 & & 32 & 13 & \\
\hline 3 & & 45 & 56 & \\
\hline 4 & & 17 & 31 & \\
\hline
\end{tabular}

$\overline{\text { Data presented as mean } \pm \text { SD. NS: } P \geq .05 \text {, Significant overall } P \text { values are indicated }}$ in bold, Significant post hoc comparisons after Bonferroni correction: ${ }^{*} P<.05$, ${ }^{* *} P<.001$, compared with control group; ${ }^{\dagger} P<.10,{ }^{\ddagger} P<.05,{ }^{\ddagger \ddagger} P<.01,{ }^{\ddagger \ddagger}{ }^{\ddagger} P<.001$, compared to nonsarcopenic COPD group. the 2 major proteolytic pathways were measured; that is, the ubiquitin-proteasome system (UPS) and the autophagy-lysosome system (autophagy), which are in part regulated by forkhead box 0 (FOXO) transcription factors, including FOXO1 and FOXO3.

\section{Progressively Increased FOXO Signaling in COPD and Sarcopenic COPD}

FOXO1 relative phosphorylation was unaltered in the skeletal muscle of nonsarcopenic COPD patients, but tended to be lower in sarcopenic COPD patients than in controls (Figure 2A). Remarkably, FOXO1 protein levels were higher in both nonsarcopenic and sarcopenic COPD patients than in controls, and were even further elevated in sarcopenic COPD patients compared with nonsarcopenic COPD patients (Figure 2C). This was paralleled by changes in FOXO1 mRNA levels, which appeared higher in both nonsarcopenic and sarcopenic COPD patients, but reached significance only in sarcopenic COPD patients compared with controls (Figure 2D). Absolute FOXO1 inhibitory phosphorylation was concomitantly increased (Figure 2B), which may reflect an adaptation to compensate for the elevated FOXO1 expression. No group differences were found in FOXO3 mRNA and protein expression or absolute phosphorylation levels (Figure $2 \mathrm{~F}-\mathrm{H}$ ); however, relative $\mathrm{FOXO} 3$ phosphorylation was lower in both nonsarcopenic and sarcopenic COPD patients than in controls (Figure 2E).

\section{Unaltered UPS Signaling}

In contrast to the apparent increase in FOXO activity, mRNA expression levels of the E3 ligases TRIM63 (tripartite motif containing 63 [MURF1]) and FBXO30 (F-box protein 30 [MUSA1]) were unaltered in the skeletal muscle of nonsarcopenic and sarcopenic COPD patients (Figure 3A, B). However, FBXO21 (F-box protein 21 [SMART]) mRNA expression was higher in sarcopenic COPD patients than in controls (Figure 3C), whereas FBXO32/MAFBX (F-box protein 32 [ATROGIN1]) mRNA expression tended to be lower in sarcopenic COPD patients than in nonsarcopenic COPD patients (Figure 3D).

\section{Progressively Increased Autophagy Signaling in COPD and} Sarcopenic COPD

Among the FOXO target genes are the autophagy-related genes $M A P 1 L C 3 B$ ( $L C 3 B$ [microtubule associated protein 1 light chain 3 beta]), SQSTM1 (P62 [sequestosome 1]), and BECN1 (Beclin1). ${ }^{26,27}$ In line with the unaltered MURF1 and MUSA1 mRNA levels, $L C 3 B$ and P62 mRNA expression remained unaltered (Figure 4D, F). BECN1 mRNA expression, however, was higher in COPD patients than in controls (Figure 4H). Interestingly, LC3BI protein expression appeared higher in both nonsarcopenic and sarcopenic COPD patients but reached significance only in sarcopenic COPD patients compared with controls, 


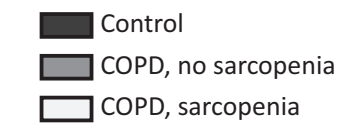

A

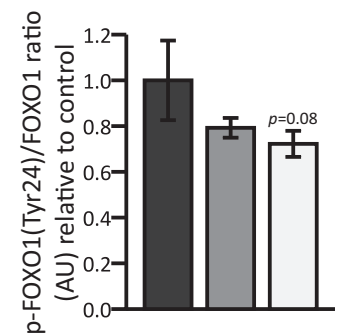

$\mathrm{E}$

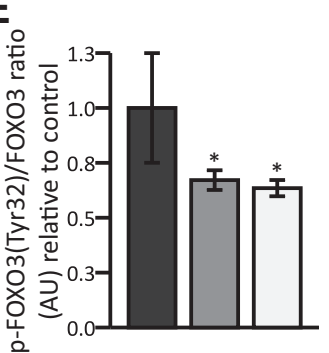

B

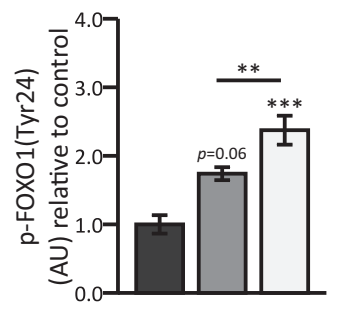

$\mathbf{F}$

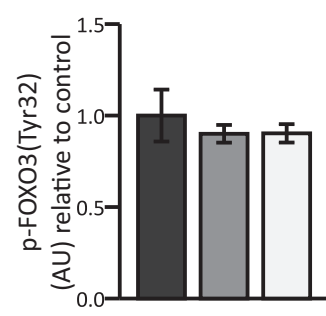

C

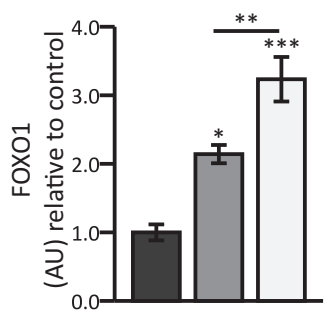

G

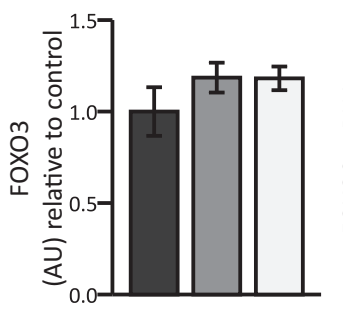

D

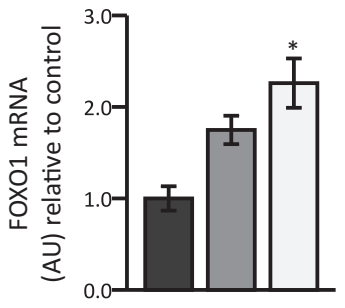

H

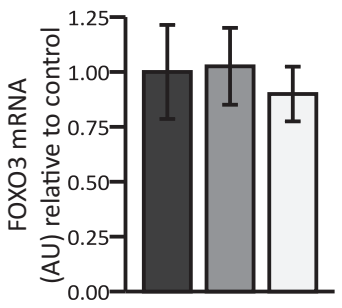

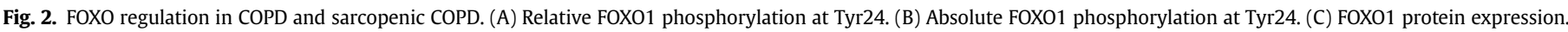

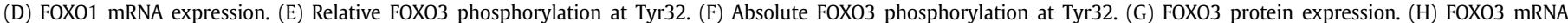
expression. Tyr, tyrosine. Values are means \pm SEM. ${ }^{*} P<.05,{ }^{* *} P<.01$, ${ }^{* * *} P<.001$, compared with control group or between indicated groups.

whereas LC3BII levels were unaltered (Figure 4B, C). The resulting lower LC3BII/I ratio in sarcopenic COPD patients than in controls (Figure 4A) implies a change in autophagic flux, although no change in P62 protein expression was observed (Figure 4E). In line with the altered LC3BII/I ratio, BECN1 protein expression seemed to be higher in sarcopenic COPD patients (Figure 4G), but this did not reach statistical significance.

An important juncture in the initiation of autophagy is activation of unc-51 like autophagy activating kinase 1 (ULK1), which is regulated through phosphorylation by the upstream kinases; mechanistic target of rapamycin (MTOR) complex 1 (MTORC1) and AMPK. ULK1 relative inhibitory phosphorylation (serine [Ser]757) was lower in both nonsarcopenic and sarcopenic COPD patients than in controls (Figure 4I), whereas relative ULK1 activating phosphorylation (Ser555) was unaltered (Figure 4K). Furthermore, absolute ULK1 Ser757 phosphorylation, and ULK1 protein and mRNA expression were unaltered (Figure 4J, M, $\mathrm{N}$ ), whereas absolute ULK1 Ser555 phosphorylation tended to be higher in sarcopenic COPD patients than in controls and nonsarcopenic COPD patients (Figure 4L).

\section{Progressively Increased AKT/MTOR Signaling in COPD and Sarcopenic COPD}

Coordination of protein degradation and protein synthesis signaling occurs via the PI3K/PKB (AKT serine/threonine kinase 1 [AKT1])/MTOR pathway. The relative phosphorylation of AKT1 was lower in the skeletal muscle of both nonsarcopenic and sarcopenic COPD patients than in controls, which tended to be more pronounced in sarcopenic COPD patients compared with nonsarcopenic COPD patients (Figure 5A). This reduced relative AKT1 phosphorylation did not result from a change in absolute AKT1 phosphorylation levels (Figure 5B) but from a higher AKT1 protein expression in nonsarcopenic and sarcopenic COPD patients than in controls, and in sarcopenic COPD patients compared with nonsarcopenic COPD patients (Figure 5C). Despite the change in AKT1 regulation, MTOR

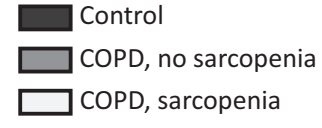

A

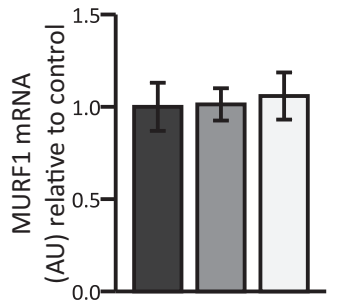

B

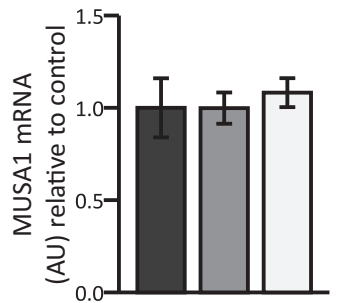

C

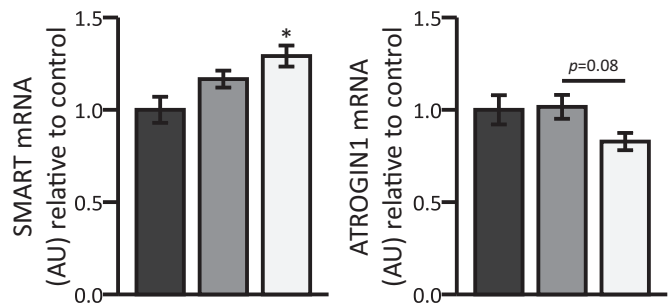

Fig. 3. mRNA expression of UPS markers in COPD and sarcopenic COPD. (A) MURF1 mRNA expression. (B) MUSA1 mRNA expression. (C) SMART mRNA expression. (D) ATROGIN1 mRNA expression. Values are means \pm SEM. ${ }^{*} P<.05$, compared with control group or between indicated groups. 
A

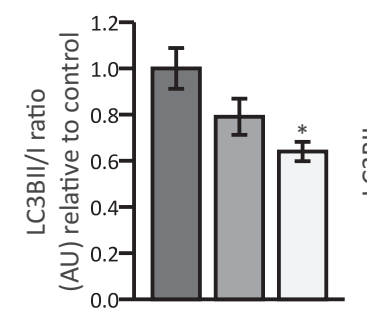

E

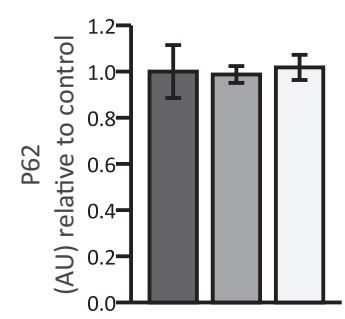

I

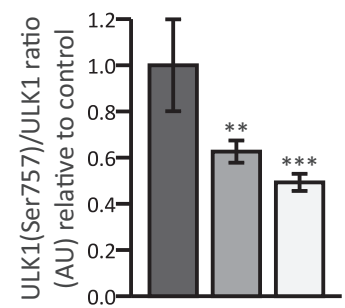

B

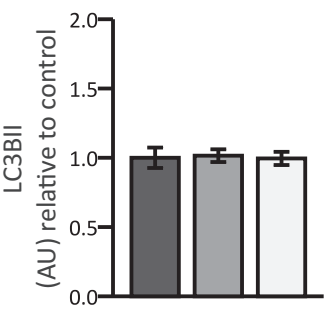

F

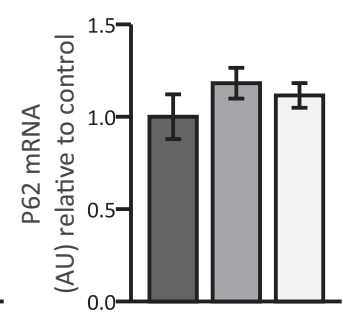

J

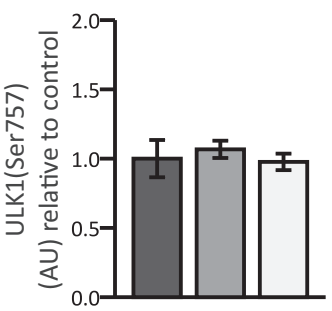

C

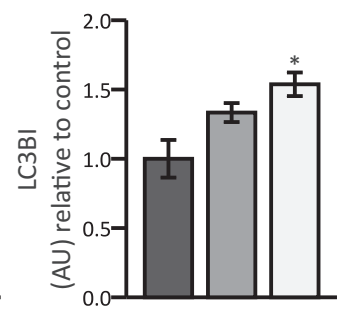

G

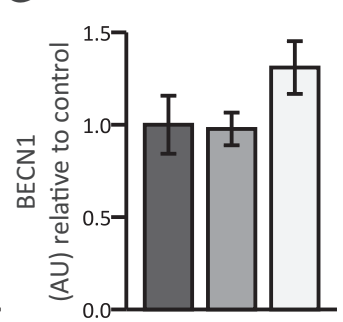

K

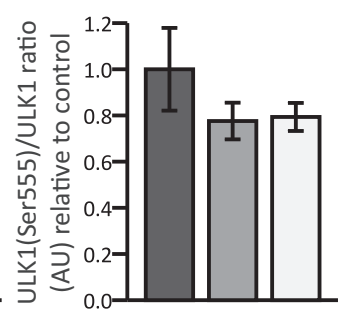

D

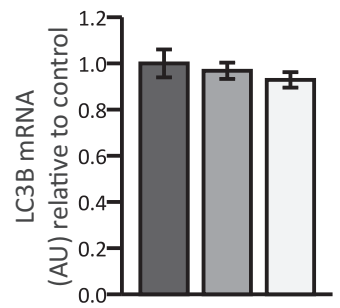

H

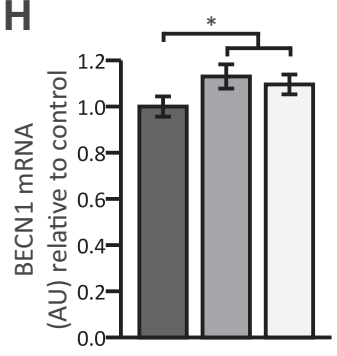

L

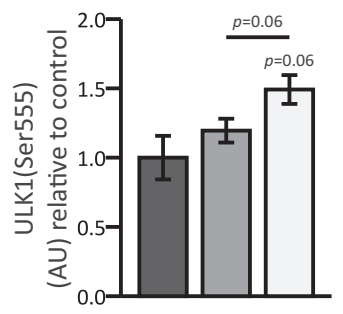

M

N
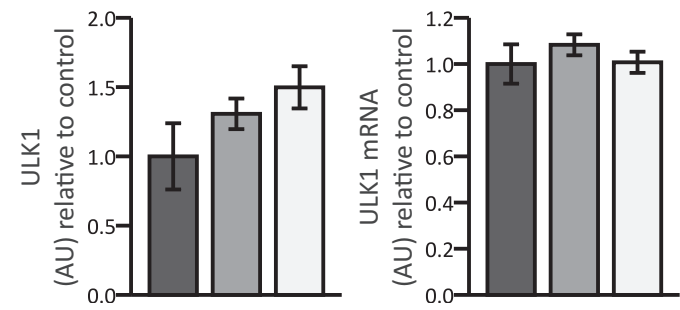

Control

COPD, no sarcopenia

COPD, sarcopenia

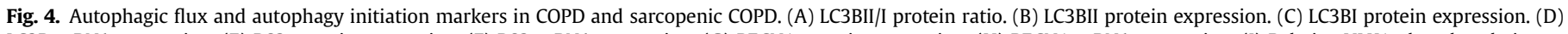

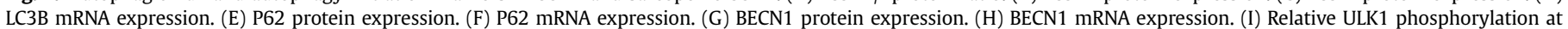

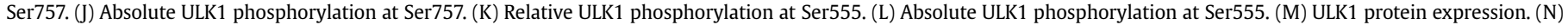
ULK1 mRNA expression. Tyr, tyrosine. Values are means \pm SEM. ${ }^{*} P<.05,{ }^{* *} P<.01,{ }^{* * *} P<.001$, compared with control group or between indicated groups.

phosphorylation (Figure 5D, E) and expression (Figure 5F) were unaltered. However, relative and absolute phosphorylation of the downstream AKT1 target glycogen synthase kinase 3 beta (GSK3B) were higher in sarcopenic COPD patients than in controls (Figure 5G-I), suggesting increased AKT1 activity.

\section{Progressively Increased Protein Synthesis Signaling in COPD and Sarcopenic COPD}

Although the MTORC1 downstream effector ribosomal protein S6 (RPS6) displayed unaltered relative phosphorylation (Figure 6A), both RPS6 protein expression and absolute phosphorylation were higher in COPD patients than in controls (Figure 6B, C). Furthermore, both relative and absolute phosphorylation of the translation repressor EIF4EBP1 (4E-BP1 [eukaryotic translation initiation factor 4E binding protein 1]) were higher in sarcopenic COPD patients than in controls (Figure 6D-F).

\section{Increased Myogenic Signaling in COPD}

Increased protein degradation and protein synthesis signaling in COPD and sarcopenic COPD suggest an increase in protein turnover. A similar pattern of molecular alterations has been observed during muscle remodeling after exercise. ${ }^{28}$ We therefore asked if myogenesis, a process that is also implicated in muscle repair and remodeling, is increased in COPD and sarcopenic COPD patients as well. To this end, markers of satellite cell function were evaluated. The mRNA expression levels of the satellite cell marker paired box 7 (PAX7) and the proliferation markers proliferating cell nuclear antigen (PCNA) and cyclin D1 (CCND1) were unaltered in nonsarcopenic and sarcopenic COPD patients (Figure 7A-C). Furthermore, the mRNA expression of myogenic factor 5 (MYF5) was unaltered (Figure 7D). In contrast, myogenic differentiation 1 (MYOD1) and myogenin (MYOG) mRNA expression was higher in COPD patients than in controls (Figure 7E, F), and CDH15 (cadherin 15 [M-cadherin]) mRNA expression showed a similar trend (Figure 7G). This 
A

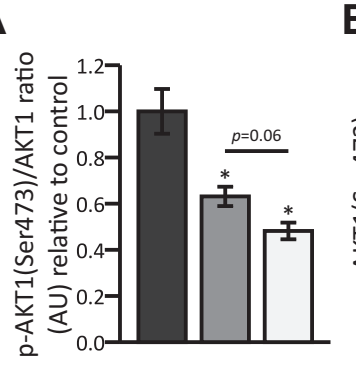

D

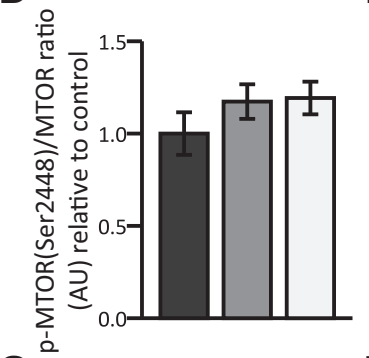

B

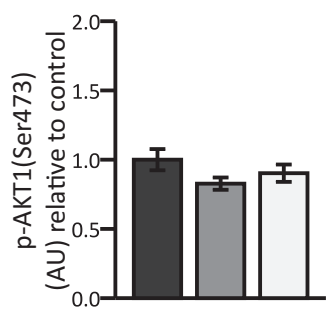

E

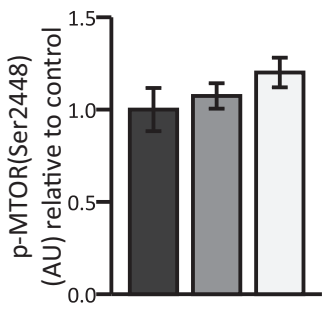

H

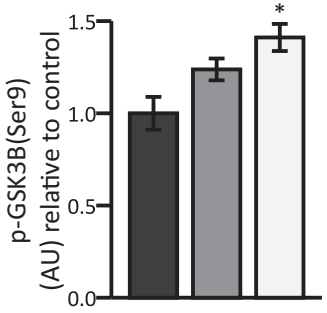

C

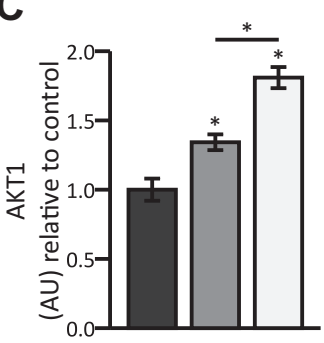

F

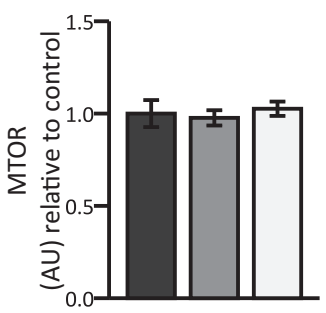

I

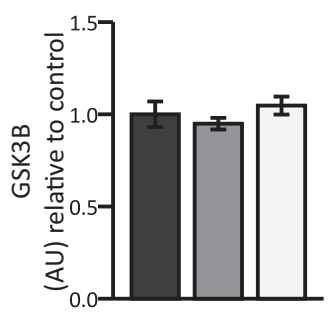

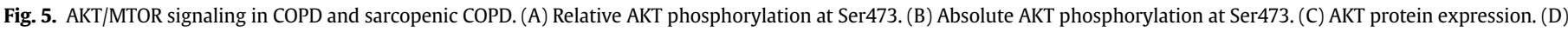

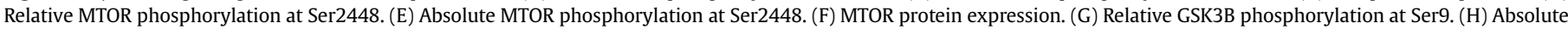
GSK3B phosphorylation at Ser9. (I) GSK3B protein expression. Tyr, tyrosine. Values are means \pm SEM. ${ }^{*} P<.05$, compared with control group or between indicated groups.

implicates a sarcopenia-independent increase in the mRNA expression of muscle differentiation markers in COPD. In discordance with these findings, which suggested increased myogenesis, the mRNA expression of the myogenesis repressor MSTN (myostatin) was higher in the skeletal muscle of both nonsarcopenic and sarcopenic COPD patients than in controls (Figure $7 \mathrm{H}$ ).
A

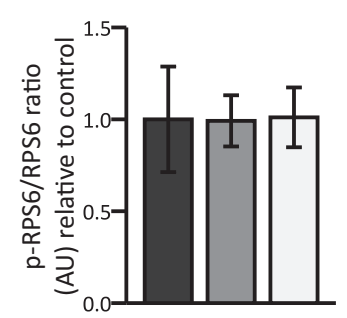

D

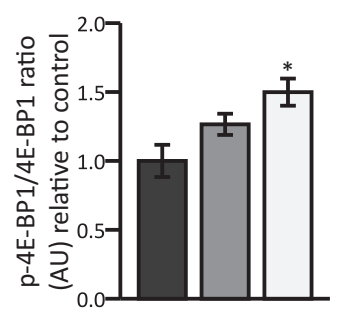

B

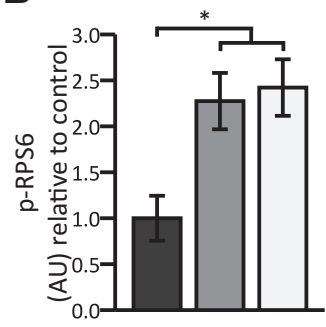

E

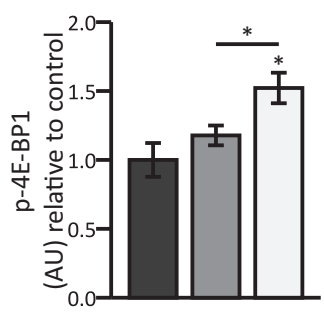

C

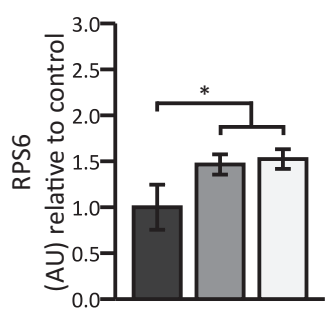

F

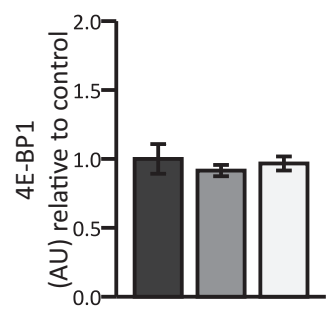

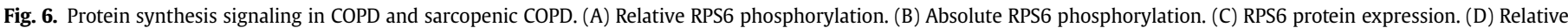

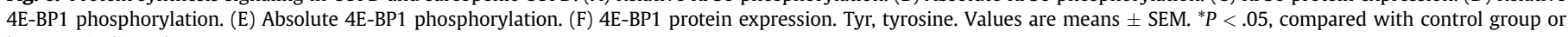
between indicated groups. 


\section{Discussion}

By assessing a comprehensive panel of molecular regulators of muscle protein turnover, we demonstrate that both protein degradation and synthesis signaling are increased in the skeletal muscles of COPD patients, and extend previous findings by showing that these alterations are even more prominent in sarcopenic COPD patients. Furthermore, we show that myogenic differentiation signaling is increased in COPD, which is maintained, but not aggravated in sarcopenic COPD.

Several studies have addressed protein degradation and/or protein synthesis signaling in COPD or sarcopenic COPD..$^{8-14,29,30}$ However, due to differences in characteristics of the control groups, differences in disease severity of the COPD populations, and differences in body composition phenotyping, these studies cannot be directly compared or combined to extrapolate a conclusion on protein turnover regulation in COPD-related sarcopenia. In the present study, we therefore measured an extensive panel of molecular markers in skeletal muscle biopsies of a large, well-phenotyped COPD cohort to assess potential differential regulation of protein degradation and synthesis in the skeletal muscle of COPD patients with and without sarcopenia, and hint toward its potential implications for the level of protein turnover. Although we recognize that muscle protein degradation and synthesis rates were not measured in this study, given that this is a general limitation of many studies in humans, coordination between signaling and rates of turnover can be extrapolated from previous studies. ${ }^{31}$

Previous studies suggested increased FOXO signaling in the skeletal muscle of COPD patients and sarcopenic COPD patients. ${ }^{11,29}$ Correspondingly, we find lower relative FOXO1 and FOXO3 inhibitory phosphorylation in COPD patients, implicating increased FOXO transcriptional activity. In line, the mRNA expression of the FOXO target SMART is higher in sarcopenic COPD patients than in controls. However, although previous reports showed increased ATROGIN $1^{8,9,13}$ and MURF1 $1^{11,29}$ expression in COPD and sarcopenic COPD, the present study shows no increase in the mRNA expression of ATROGIN1, MURF1, or MUSA1. In agreement with the study of Natanek et $\mathrm{al},{ }^{30}$ ATROGIN1
mRNA expression even tends to be lower in sarcopenic COPD patients than in nonsarcopenic COPD patients. Although the current data seem in disagreement with some of the previous literature, we and others have suggested that the increased expression of E3 ligases might be a feature of acute catabolic events rather than chronic muscle wasting, ${ }^{30,32,33}$ the latter of which was studied in this cohort. We speculate that a recurring rise in UPS activity during repeated disease exacerbations results in an increased capacity for UPS induction, rendering the skeletal muscle more susceptible to catabolic triggers. $^{34,35}$ The higher FOXO1 protein and mRNA expression levels in muscle tissue of COPD patients and sarcopenic COPD patients may reflect such an increase in UPS inductive capacity. In this regard, the elevated absolute FOXO1 phosphorylation level may serve as a compensatory inhibition of (excess) protein degradation signaling in the stable disease phase.

In line with unaltered E3 ligase expression, the mRNA expression of autophagy-related FOXO target genes, $L C 3 B$ and $P 62$, is unchanged in COPD and sarcopenic COPD patients. Nonetheless, the higher BECN1 mRNA expression level in COPD patients than in controls, and the apparent elevation in BECN1 protein expression in sarcopenic compared with nonsarcopenic COPD patients hint toward increased autophagy in COPD and sarcopenic COPD. It was previously shown that the number of autophagosomes is higher in the skeletal muscle of COPD patients and muscle-wasted COPD patients than in controls. ${ }^{14,29}$ Although autophagic flux cannot be measured in vivo in humans, the lower LC3BI/I ratio in sarcopenic COPD patients compared with controls indicates that the level of autophagic flux is altered. The relative inhibitory phosphorylation (Ser757) of ULK1, an important juncture in autophagy initiation, is lower in COPD patients than in controls. Furthermore, the absolute Ser555 phosphorylation level tends to be higher in sarcopenic COPD patients than in controls or nonsarcopenic COPD patients. Together, this suggests that in the skeletal muscle of COPD patients, and even more prominent in sarcopenic COPD patients, autophagy is increased.

Higher absolute FOXO1 phosphorylation levels in COPD and sarcopenic COPD patients can result from increased AKT1 activity.

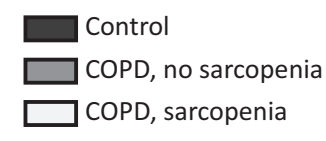

A

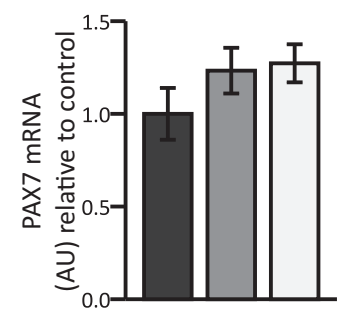

E

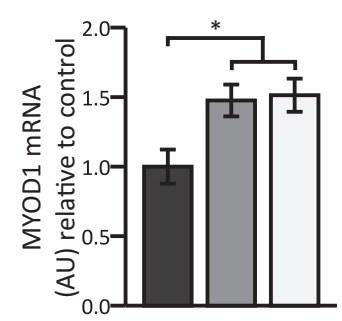

B

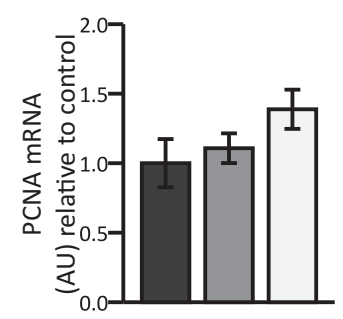

$\mathbf{F}$

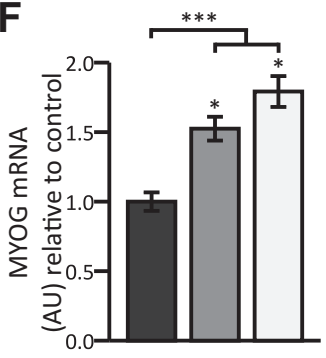

C

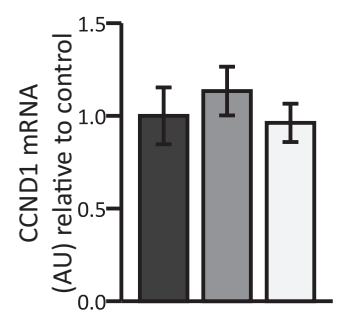

G

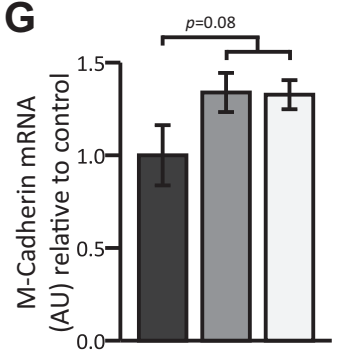

D
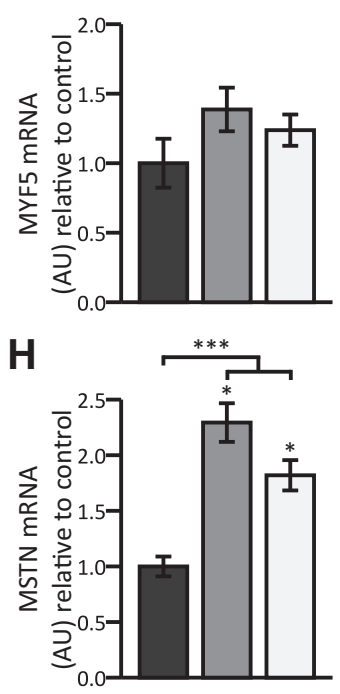

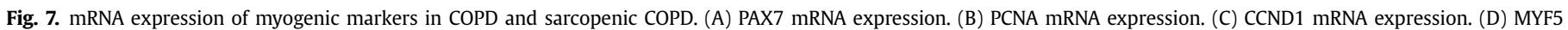

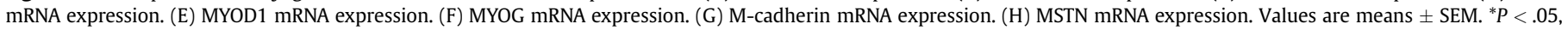
${ }^{* * *} P<.001$, compared with control group. 
However, several previous studies suggested a decreased AKT1 activity in COPD and sarcopenic COPD based on the relative AKT1 phosphorylation. $^{11,14}$ In line with this, we find lower relative AKT1 phosphorylation in nonsarcopenic COPD patients than in controls, and a trend toward a further decrease in sarcopenic COPD patients compared with nonsarcopenic COPD patients. Notably, the lower AKT1 relative phosphorylation is not reflective of altered absolute AKT1 phosphorylation, but rather of higher AKT1 protein expression. Moreover, phosphorylation levels of other downstream targets of AKT1 (ie, GSK3B, RPS6, 4E-BP1) suggest increased AKT1 activity. This stresses the need to not merely predict the enzymatic activity of phosphoproteins based on their relative phosphorylation state, but to also consider alterations in total protein abundance. Indeed, although the relative RPS6 phosphorylation remains unaltered, both the expression and activating phosphorylation level of RPS6 are higher in COPD patients than in controls, which is suggestive of increased mRNA translation capacity. Furthermore, the absolute inhibitory phosphorylation level of the negative regulators of translation initiation, GSK3B and 4E-BP1, is higher in sarcopenic COPD patients than in controls, implicating increased mRNA translation initiation. Together, these results show that the stimulatory signaling and capacity for protein synthesis is increased in the skeletal muscle of COPD patients in a stable disease state, particularly in those with sarcopenia.

Alterations in protein turnover are not necessarily accompanied by changes in muscle mass, and may serve several physiological processes, including muscle remodeling. ${ }^{28}$ For example, recovery from muscle injury caused by eccentric exercise is accompanied by an increase in protein synthesis signaling. ${ }^{36}$ Furthermore, a recent study showed an induction of autophagy during recovery from muscle injury and suggested a role for autophagy in muscle regeneration. ${ }^{37}$ In the present study, muscle biopsies were taken at a basal state. Therefore, the increased autophagy and protein synthesis signaling suggest ongoing skeletal muscle remodeling in COPD and sarcopenic COPD patients, which may relate to muscle phenotypic alterations or damage repair. Indeed, previous studies showed damage of sarcomeres in the skeletal muscle of cachectic COPD patients. ${ }^{29}$ Furthermore, recovery from muscle damaging eccentric exercise is accompanied by an increase in skeletal muscle satellite cell content, ${ }^{38}$ which is indicative of myogenesis. Thèriault et $\mathrm{al}^{39}$ reported unaltered satellite cell numbers in COPD patients with and without muscle wasting, whereas the number of central nuclei was higher in COPD patients with preserved muscle mass. Based on myogenic regulatory factor (MRF) protein expression, they suggested that satellite cells in COPD are under a sustained proliferative state. The current study, however, shows no change in the mRNA expression of PAX7, PCNA, and $C C N D 1$, suggesting no alteration in satellite cell numbers or proliferation in muscle of COPD patients. Furthermore, MYF5 mRNA expression is unaltered, whereas the mRNA expression levels of $M$-cadherin and the MRFs, MYOD1 and MYOG, are higher in COPD patients than in controls. Together, this points toward increased myogenic differentiation signaling in COPD, which is maintained, but not aggravated, in sarcopenic COPD.

Strikingly, but in line with previous research, ${ }^{13}$ MSTN mRNA expression is higher in the skeletal muscle of COPD patients than in controls. MSTN is commonly known as a negative regulator of protein synthesis and myogenesis. ${ }^{40}$ However, when considering the seemingly contradictory increase in expression of both MSTN and MRFs in COPD, it should be taken into account that the effect of MSTN is context dependent. ${ }^{41,42}$ In vitro data showed that MSTN negatively affects myoblast proliferation and myogenic differentiation, ${ }^{43,44}$ and in vivo MSTN deficiency elevates satellite cell numbers due to increased self-renewal. ${ }^{41}$ As such, it seems obvious that proliferation is inhibited by MSTN. However, the inhibitory effect of MSTN on cell cycle progression, ${ }^{41}$ often interpreted as detrimental for myogenesis, may actually facilitate terminal differentiation. ${ }^{42,45}$ The higher MSTN and MRF mRNA expression in COPD may therefore be a physiological response to promote terminal differentiation as part of an increased demand for myonuclear accretion. Importantly, several studies suggest that temporal expression of MSTN controls the balance between proliferation and differentiation of satellite cells. ${ }^{41,46,47}$ A sustained elevation of MSTN expression may therefore impair satellite cell activation and negatively regulate self-renewal, ${ }^{41}$ eventually resulting in satellite cell senescence and depletion of the satellite cell pool. ${ }^{42,48}$

In conclusion, these results confirm increased protein degradation and synthesis signaling in the skeletal muscle of COPD patients compared with controls and show further stimulation of these processes in sarcopenic COPD patients compared with nonsarcopenic COPD patients. Together with the increase in myogenic signaling, this mirrors molecular alterations observed during muscle repair and remodeling (Figure 8).

\section{Implications and Future Perspectives}

Factors implicated in COPD-related sarcopenia, including oxidative stress and inflammation, ${ }^{32}$ can result from and cause cellular damage, ${ }^{49,50}$ and may drive repair and remodeling-like molecular alterations. Although these molecular alterations are likely necessary to facilitate repair of myofiber damage, a sustained increase in protein turnover regulation elevates the energetic costs of protein metabolism, ${ }^{51}$ whereas a sustained increase in myogenic signaling could result in satellite cell

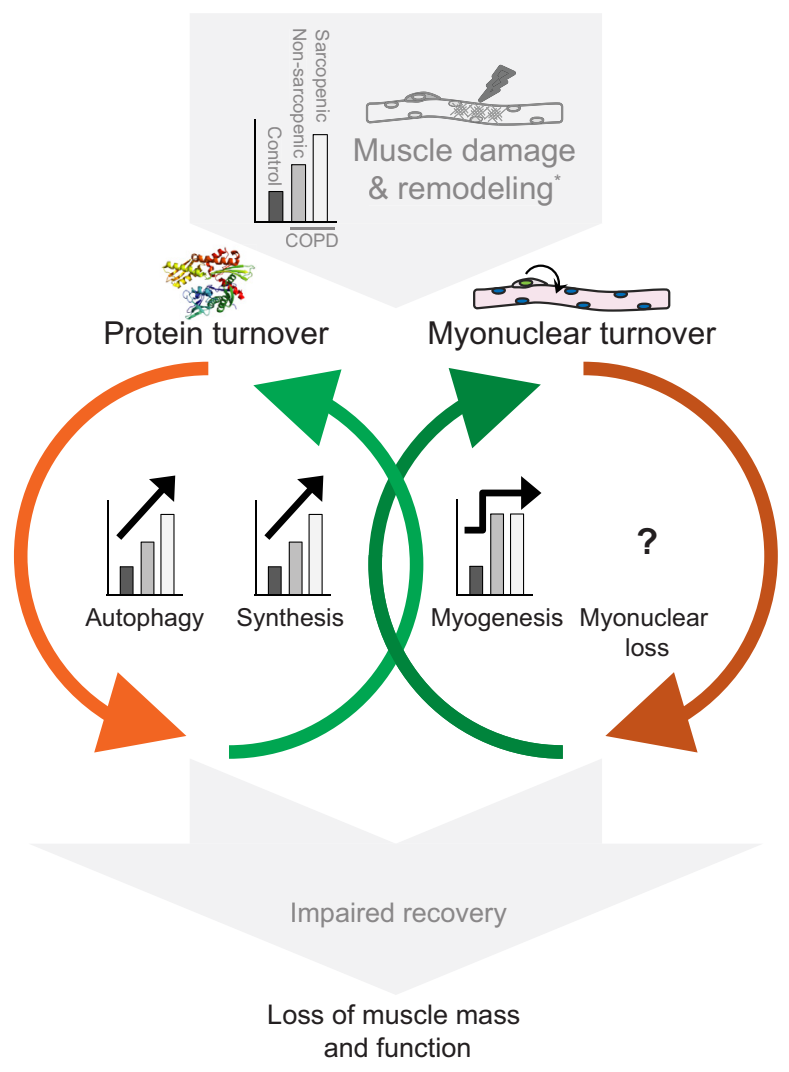

Fig. 8. Schematic presentation of sarcopenia-related molecular alterations in COPD. COPD-related factors leading to muscle damage and remodeling may drive the increase in myogenic and protein turnover signaling in COPD, as well as the even further increased protein turnover signaling in sarcopenic COPD, which may impair recovery after an exacerbation, leading to a progressive loss of muscle mass and function. Black text represents the regulation of indicated processes as measured in the current study, whereas gray text represents their associations and implications from previous literature. *Puig-Vilanova et al. ${ }^{29}$ 
depletion. This may not affect muscle mass substantially in a stable disease state, but it remains elusive to what extent this affects the coordination between anabolic signaling and the anabolic response required for muscle mass recovery after an exacerbation.

Future studies should therefore address the underlying mechanisms and pathophysiological relevance of repair and remodeling in the context of physiological responses to anabolic and catabolic stimuli in COPD patients, to elucidate the role of altered protein turnover and myogenic regulation in the development and treatment of COPD-related sarcopenia.

\section{References}

1. Cao L, Morley JE. Sarcopenia is recognized as an independent condition by an International Classification of Diseases, Tenth Revision, Clinical Modification (ICD-10-CM) code. J Am Med Dir Assoc 2016;17:675-677.

2. van de Bool C, Gosker HR, van den Borst B, et al. Muscle quality is more impaired in sarcopenic patients with chronic obstructive pulmonary disease. J Am Med Dir Assoc 2016:17:415-420.

3. Mostert R, Goris A, Weling-Scheepers C, et al. Tissue depletion and health related quality of life in patients with chronic obstructive pulmonary disease. Respir Med 2000:94:859-867.

4. Engelen MP, Schols AM, Baken WC, et al. Nutritional depletion in relation to respiratory and peripheral skeletal muscle function in out-patients with COPD. Eur Respir J 1994;7:1793-1797.

5. Vestbo J, Prescott E, Almdal T, et al. Body mass, fat-free body mass, and prognosis in patients with chronic obstructive pulmonary disease from a random population sample: Findings from the Copenhagen City Heart Study. Am J Respir Crit Care Med 2006:173:79-83.

6. Schols AM, Broekhuizen R, Weling-Scheepers CA, et al. Body composition and mortality in chronic obstructive pulmonary disease. Am J Clin Nutr 2005;82:53-59.

7. Maters GA, de Voogd JN, Sanderman R, et al. Predictors of all-cause mortality in patients with stable COPD: Medical co-morbid conditions or high depressive symptoms. COPD 2014;11:468-474.

8. Fermoselle C, Rabinovich R, Ausin P, et al. Does oxidative stress modulate limb muscle atrophy in severe COPD patients? Eur Respir J 2012;40:851-862.

9. Vogiatzis I, Simoes DC, Stratakos G, et al. Effect of pulmonary rehabilitation on muscle remodelling in cachectic patients with COPD. Eur Respir J 2010;36: $301-310$.

10. Debigare R, Maltais F, Cote $\mathrm{CH}$, et al. Profiling of mRNA expression in quadriceps of patients with COPD and muscle wasting. COPD 2008;5:75-84.

11. Doucet M, Russell AP, Leger B, et al. Muscle atrophy and hypertrophy signaling in patients with chronic obstructive pulmonary disease. Am J Respir Crit Care Med 2007;176:261-269.

12. Lemire BB, Debigare R, Dube A, et al. MAPK signaling in the quadriceps of patients with chronic obstructive pulmonary disease. J Appl Physiol (1985) 2012;113:159-166.

13. Plant PJ, Brooks D, Faughnan M, et al. Cellular markers of muscle atrophy in chronic obstructive pulmonary disease. Am J Respir Cell Mol Biol 2010;42:461-471.

14. Guo Y, Gosker HR, Schols AM, et al. Autophagy in locomotor muscles of patients with chronic obstructive pulmonary disease. Am J Respir Crit Care Med 2013:188:1313-1320.

15. Lewis A, Riddoch-Contreras J, Natanek SA, et al. Downregulation of the serum response factor/miR-1 axis in the quadriceps of patients with COPD. Thorax 2012:67:26-34.

16. Engelen MP, Deutz NE, Wouters EF, et al. Enhanced levels of whole-body protein turnover in patients with chronic obstructive pulmonary disease. Am J Respir Crit Care Med 2000;162:1488-1492.

17. Chung JH, Hwang $\mathrm{HJ}$, Han $\mathrm{CH}$, et al. Association between sarcopenia and metabolic syndrome in chronic obstructive pulmonary disease: The Korea National Health and Nutrition Examination Survey (KNHANES) from 2008 to 2011. COPD 2015:12:82-89.

18. Jones SE, Maddocks M, Kon SS, et al. Sarcopenia in COPD: Prevalence, clinical correlates and response to pulmonary rehabilitation. Thorax 2015;70:213-218.

19. Vermeeren MA, Creutzberg EC, Schols AM, et al. Prevalence of nutritional depletion in a large out-patient population of patients with COPD. Respir Med 2006;100:1349-1355.

20. van den Borst B, Slot IG, Hellwig VA, et al. Loss of quadriceps muscle oxidative phenotype and decreased endurance in patients with mild-to-moderate COPD. J Appl Physiol (1985) 2013;114:1319-1328.

21. Cebron Lipovec N, Schols AM, van den Borst B, et al. Sarcopenia in advanced COPD affects cardiometabolic risk reduction by short-term high-intensity pulmonary rehabilitation. J Am Med Dir Assoc 2016;17:814-820.

22. Newman AB, Kupelian V, Visser M, et al. Sarcopenia: Alternative definitions and associations with lower extremity function. J Am Geriatr Soc 2003;51:1602-1609.
23. Miller MR, Crapo R, Hankinson J, et al. General considerations for lung function testing. Eur Respir J 2005;26:153-161.

24. Vestbo J, Hurd SS, Agusti AG, et al. Global Strategy for the diagnosis, management, and prevention of chronic obstructive pulmonary disease GOLD executive summary. Am J Respir Crit Care Med 2013;187:347-365.

25. Franssen FM, Sauerwein HP, Ackermans MT, et al. Increased postabsorptive and exercise-induced whole-body glucose production in patients with chronic obstructive pulmonary disease. Metabolism 2011;60:957-964.

26. Milan G, Romanello V, Pescatore F, et al. Regulation of autophagy and the ubiquitin-proteasome system by the FoxO transcriptional network during muscle atrophy. Nat Commun 2015;6:6670.

27. Lapierre LR, Kumsta C, Sandri M, et al. Transcriptional and epigenetic regulation of autophagy in aging. Autophagy 2015;11:867-880.

28. Hesselink MK, Minnaard R, Schrauwen P. Eat the meat or feed the meat: Protein turnover in remodeling muscle. Curr Opin Clin Nutr Metab Care 2006; 9:672-676.

29. Puig-Vilanova E, Rodriguez DA, Lloreta J, et al. Oxidative stress, redox signaling pathways, and autophagy in cachectic muscles of male patients with advanced COPD and lung cancer. Free Radic Biol Med 2015;79:91-108.

30. Natanek SA, Riddoch-Contreras J, Marsh GS, et al. MuRF-1 and atrogin-1 protein expression and quadriceps fiber size and muscle mass in stable patients with COPD. COPD 2013;10:618-624.

31. Atherton PJ, Etheridge T, Watt PW, et al. Muscle full effect after oral protein: Time-dependent concordance and discordance between human muscle protein synthesis and mTORC1 signaling. Am J Clin Nutr 2010;92:1080-1088.

32. Langen RC, Gosker HR, Remels AH, et al. Triggers and mechanisms of skeletal muscle wasting in chronic obstructive pulmonary disease. Int J Biochem Cell Biol 2013;45:2245-2256.

33. Sacheck JM, Hyatt JP, Raffaello A, et al. Rapid disuse and denervation atrophy involve transcriptional changes similar to those of muscle wasting during systemic diseases. FASEB J 2007;21:140-155.

34. Hopkinson NS, Tennant RC, Dayer MJ, et al. A prospective study of decline in fat free mass and skeletal muscle strength in chronic obstructive pulmonary disease. Respir Res 2007;8:25.

35. Alahmari AD, Kowlessar BS, Patel AR, et al. Physical activity and exercise capacity in patients with moderate COPD exacerbations. Eur Respir J 2016;48: 340-349.

36. Michailidis Y, Karagounis LG, Terzis G, et al. Thiol-based antioxidant supplementation alters human skeletal muscle signaling and attenuates its inflammatory response and recovery after intense eccentric exercise. Am J Clin Nutr 2013:98:233-245.

37. Nichenko AS, Southern WM, Atuan M, et al. Mitochondrial maintenance via autophagy contributes to functional skeletal muscle regeneration and remodeling. Am J Physiol Cell Physiol 2016;311:C190-C200.

38. Cermak NM, Snijders T, McKay BR, et al. Eccentric exercise increases satellite cell content in type II muscle fibers. Med Sci Sports Exerc 2013;45:230-237.

39. Thèriault ME Pare ME Lemire $B B$, et al. Regenerative defect in vastus lateralis muscle of patients with chronic obstructive pulmonary disease. Respir Res 2014;15:35.

40. Trendelenburg AU, Meyer A, Rohner D, et al. Myostatin reduces Akt/TORC1 p70S6K signaling, inhibiting myoblast differentiation and myotube size. Am Physiol Cell Physiol 2009;296:C1258-C1270.

41. McCroskery S, Thomas M, Maxwell L, et al. Myostatin negatively regulates satellite cell activation and self-renewal. J Cell Biol 2003;162:1135-1147.

42. Manceau M, Gros J, Savage K, et al. Myostatin promotes the terminal differentiation of embryonic muscle progenitors. Genes Devel 2008;22:668-681.

43. Langley B, Thomas M, Bishop A, et al. Myostatin inhibits myoblast differentiation by down-regulating MyoD expression. J Biol Chem 2002;277: 49831-49840.

44. Steelman CA, Recknor JC, Nettleton D, et al. Transcriptional profiling of myostatin-knockout mice implicates Wnt signaling in postnatal skeletal muscle growth and hypertrophy. FASEB J 2006;20:580-582.

45. Bernardi H, Gay S, Fedon Y, et al. Wnt4 activates the canonical beta-catenin pathway and regulates negatively myostatin: Functional implication in myogenesis. Am J Physiol Cell Physiol 2011;300:C1122-C1138.

46. Rossi G, Antonini S, Bonfanti C, et al. Nfix regulates temporal progression of muscle regeneration through modulation of myostatin expression. Cell Rep 2016; $14: 2238-2249$

47. George RM, Biressi S, Beres BJ, et al. Numb-deficient satellite cells have regeneration and proliferation defects. Proc Natl Acad Sci U S A 2013;110: 18549-18554.

48. Le Grand F, Rudnicki MA. Skeletal muscle satellite cells and adult myogenesis. Curr Opin Cell Biol 2007;19:628-633.

49. Chen GY, Nunez G. Sterile inflammation: Sensing and reacting to damage. Nat Rev Immunol 2010;10:826-837.

50. Demple B, Harrison L. Repair of oxidative damage to DNA: Enzymology and biology. Ann Rev Biochem 1994;63:915-948.

51. Bier DM. The Role of Protein and Amino Acids in Sustaining and Enhancing Performance. The Energy Costs of Protein Metabolism: Lean and Mean on Uncle Sam's Team. Washington, DC: National Academies Press; 1999. 


\section{Supplementary Methods}

\section{Reverse Transcriptase-Quantitative Polymerase Chain Reaction}

Tissue was homogenized (Mini-BeadBeater; Biospec Products, Bartlesville, OK) in the presence of TRI-reagent (Sigma-Aldrich, St Louis, $\mathrm{MO}$ ), and RNA was isolated by TRI-reagent/chloroform extraction and subsequently precipitated from the aqueous phase using glycogencontaining isopropanol. RNA was reconstituted in $30 \mu \mathrm{L}$ RNA storage solution (AM7001; Ambion, Austin, TX) and stored at $-80^{\circ} \mathrm{C}$. RNA concentrations were measured spectrophotometrically using a Nanodrop UV-Vis spectrophotometer (ND-1000; Thermo Scientific, Waltham, MA). A total of 400 ng RNA was diluted in nuclease-free $\mathrm{H}_{2} \mathrm{O}$ and reverse transcribed to cDNA using the Tetro cDNA synthesis kit (Bioline, Taunton, MA) according to the manufacturer's instructions. Quantitative polymerase chain reaction ( $\mathrm{qPCR}$ ) primers were designed based on Ensembl transcript sequences and ordered from Sigma Genosys (Zwijndrecht, the Netherlands), with primer details shown in Table E1. qPCR reactions contained Sensimix SYBR and ROX (GC Biotech, Alphen aan den Rijn, the Netherlands) and primer mix, and were run in a 384-well white opaque plate (Roche, Basel, Switzerland) on a LightCycler 480 system (Roche). Melting curves were analyzed to verify specificity of the amplification, and relative quantity of the targets was assessed by LinRegPCR software (v2014.8; bioinfo@amc.uva.nl). ${ }^{1}$ Three reference genes (RPLP0, B2M, and PPIA) were used to calculate a GeNorm correction factor, which was used to normalize expression levels of the target genes.

\section{Western Blot}

Tissue was homogenized in $600 \mu \mathrm{L}$ immunoprecipitation lysis buffer (50 mM Tris, $150 \mathrm{mM} \mathrm{NaCl}, 10 \%$ glycerol, $0.5 \%$ Nonidet P40, protease and phosphatase inhibitors [Roche]) with a Micro Tissue Homogenizer (Kimble-Kontes, Vineland, NJ). After homogenization, samples were incubated on a tube rotator at $4{ }^{\circ} \mathrm{C}$ for 30 minutes and centrifuged at $14,000 \mathrm{~g}$ at $4^{\circ} \mathrm{C}$ for 30 minutes. The supernatant was stored at $-80^{\circ} \mathrm{C}$ until analysis. Total protein concentration was determined using a BCA Protein Assay kit (Pierce Biotechnology, Waltham, MA) according to the manufacturer's instructions. For Western blot analyses, $4 \times$ Laemmli sample buffer $(0.25 \mathrm{M}$ Tris-HCL pH 6.8, 8\% [wt/vol] sodium dodecyl sulfate, $40 \%$ [vol/vol] glycerol, $0.4 \mathrm{M}$ dithiothreitol, and $0.02 \%$ [wt/vol] Bromophenol Blue) was added and samples were heated to $100^{\circ} \mathrm{C}$ for 5 minutes; $10 \mu$ g protein was separated on a Criterion XT Precast 4-12\% Bis-Tris gel (Bio-Rad, Hercules, CA) in XT MOPS running buffer (Bio-Rad) by gel electrophoresis. Proteins were transferred to a nitrocellulose membrane (Bio-Rad) by electroblotting at $100 \mathrm{~V}$ for 60 minutes in transfer buffer (25 mM Tris, $192 \mathrm{mM}$ glycine, 20\% [vol/vol] methanol).

For total protein detection, the membrane was stained with PonceauS solution ( $0.2 \%$ PonceauS in $1 \%$ acetic acid; Sigma-Aldrich Chemie, Taufkirchen, Germany) and imaged using the Amersham imager 600RGB (GE Healthcare, Pittsburgh, PA). The membrane was blocked for 1 hour at room temperature (RT) in Tris-buffered saline with Tween20 (TBST; 20 mM Tris, $137 \mathrm{mM} \mathrm{NaCl,} \mathrm{0.1 \%} \mathrm{[vol/vol]} \mathrm{Tween20,} \mathrm{pH} \mathrm{7.6)}$ containing 3\% (wt/vol) nonfat dry milk (Campina, Eindhoven, the Netherlands). The membranes were washed in TBST, followed by overnight incubation at $4^{\circ} \mathrm{C}$ with primary antibody diluted in TBST with $3 \%$ bovine serum albumin or nonfat dry milk (Table E2). Membranes were incubated with a peroxidase-conjugated secondary antibody solution (\#PI-1000, diluted 1:10,000 in blocking solution; Vector Laboratories, Burlingame, CA) for 1 hour at RT, and targets were visualized by chemiluminescence using Supersignal West PICO or FEMTO Chemiluminescent Substrate (Pierce Biotechnology) according to the manufacturer's instructions, and detected using the Amersham imager 600RGB. Signals were quantified with Image Quant software (Amersham). For analyses, samples from controls and patients with chronic obstructive pulmonary disease (COPD) were randomly distributed within and between blots, and reference samples were loaded onto all blots to correct for between-blot variation. Protein expression and phosphorylation levels were corrected for total protein content, and presented as a fold change compared with the control group.

\section{Reference}

1. Ramakers C, Ruijter JM, Deprez RH, et al. Assumption-free analysis of quantitative real-time polymerase chain reaction (PCR) data. Neurosci Lett 2003;339: $62-66$. 
Table E1

qPCR Primer Sequences of Genes of Interest and Reference Genes

\begin{tabular}{|c|c|c|c|c|}
\hline Target & $\mathrm{n}^{*}$ & Source & Forward & Reverse \\
\hline FOXO1 & $13 / 51 / 38$ & ENSG00000150907 & CCTGGACATGCTCAGCAGACATC & TTGGGTCAGGCGGTTCATACC \\
\hline FOXO3 & $13 / 51 / 38$ & ENSG00000118689 & CACTGGTGCTAAGCAGGCCTCAT & ATGGCGTGGGATTCACAAAGGT \\
\hline MURF1 & $13 / 51 / 38$ & ENSG00000158022 & GCGAGGTGGCCCCATT & GATGGTCTGCACACGGTCATT \\
\hline MUSA1 & $13 / 50 / 38$ & ENSG00000118496 & AGTACTCCTGACAGCAGCAG & CATTGACACAGAAGTCAATCACTC \\
\hline SMART & $13 / 50 / 38$ & ENSG00000135108 & AATTAATCTGAAAGGCACTGTGTC & TGAAGACAGAATGTCACAAACTG \\
\hline ATROGIN1 & $13 / 51 / 38$ & ENSG00000156804 & GAAGAAACTCTGCCAGTACCACTTC & CCСTTTGTCTGACAGAATTAATCG \\
\hline$L C 3 B$ & $13 / 51 / 38$ & ENSG00000140941 & ACCATGCCGTCGGAGAAGAC & TCTCGAATAAGTCGGACATCTTCTACTCT \\
\hline P62 & $13 / 51 / 38$ & ENSG00000161011 & GGTGCACCCCAATGTGATCT & CGCAGACGCTACACAAGTCG \\
\hline$B E C N 1$ & $13 / 51 / 38$ & ENSG00000126581 & AATGCAACCTTCCACATCTGGC & CCCAGCCTGAAGTTATTGATTGTGC \\
\hline ULK1 & $13 / 50 / 38$ & ENSG00000177169 & TGCCCGGTGTCCTGGTCCTC & CAGGGGCAGCAGTTGAGGCG \\
\hline PAX7 & $13 / 50 / 38$ & ENSG00000009709 & TACAGCACCACCGGCTACAGCGTG & CTGGCCGTACTGGCCGTACTGATAG \\
\hline PCNA & $13 / 50 / 38$ & ENSG00000132646 & TCTGCAAGTGGAGAACTTGGAA & GAAGTTCAGGTACCTCAGTGCAA \\
\hline CCND1 & $13 / 50 / 38$ & ENSG00000110092 & ACCGCCTCACACGCTTCCTCT & GCCTGGCGCAGGCTTGACTC \\
\hline MYF5 & $13 / 50 / 38$ & ENSG00000111049 & TGCCCGAATGTAACAGTCCT & AGCAATCCAAGCTGGATAAGG \\
\hline MYOD1 & $13 / 51 / 38$ & ENSG00000129152 & CAATCCAAACCAGCGGTTGC & CCTCGATATAGCGGATGGCGT \\
\hline MYOG & $13 / 51 / 38$ & ENSG00000122180 & TCAGCGCCAACCCAGG & GGTGAGGGAGTGCAGGTTGT \\
\hline M-cadherin & $13 / 50 / 38$ & ENSG00000129910 & CCTGGACATCGCCGACTTCA & TGGGGTCACTATCTGCAGCC \\
\hline MSTN & $13 / 51 / 38$ & ENSG00000138379 & AACCTTCCCAGGACCAGGAGAA & TGTCTGTTACCTTGACCTCTAAAAACGG \\
\hline RPLPO & $13 / 51 / 38$ & ENSG00000089157 & TCTACAACCCTGAAGTGCTTGATATC & GCAGACAGACACTGGCAACATT \\
\hline$B 2 M$ & $13 / 51 / 38$ & ENSG00000196262 & CATCTGCACTGCCAAGACTGA & TTCATGCCTTCTTTCACTTTGC \\
\hline PPIA & $13 / 51 / 38$ & ENSG00000166710 & CTGTGCTCGCGCTACTCTCTCTT & TGAGTAAACCTGAATCTTTGGAGTACGC \\
\hline
\end{tabular}

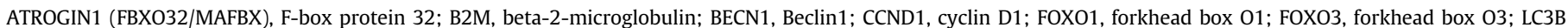

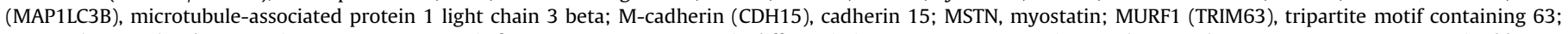

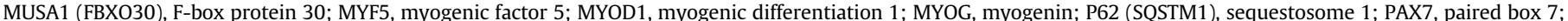

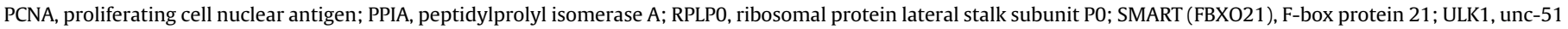
like autophagy activating kinase 1 .

*Sample size (controls/nonsarcopenic patients with COPD patients/sarcopenic patients with COPD).

Table E2

Primary Antibody List

\begin{tabular}{lllc}
\hline Target & $\mathrm{n}^{*}$ & Supplier & Product No. \\
\hline FOXO1 & $12 / 52 / 38$ & Cell Signaling & 2880 \\
FOXO3 & $12 / 52 / 38$ & Cell Signaling & 2497 \\
FOXO1 (Tyr24)/FOXO3(Tyr32) & $11 / 52 / 38$ & Cell Signaling & 9464 \\
LC3B & $12 / 52 / 38$ & Cell Signaling & 2775 \\
P62 & $12 / 53 / 38$ & Cell Signaling & 5114 \\
BECN1 & $12 / 53 / 38$ & Novus Biologicals & NB110-87318SS \\
ULK1 & $12 / 53 / 38$ & Cell Signaling & 8054 \\
ULK1(Ser757) & $12 / 53 / 38$ & Cell Signaling & 6888 \\
ULK1(Ser555) & $12 / 53 / 38$ & Cell Signaling & 5869 \\
AKT1 & $12 / 53 / 39$ & Cell Signaling & 2920 \\
AKT(Ser473) & $12 / 53 / 39$ & Cell Signaling & 4060 \\
MTOR & $11 / 53 / 39$ & Cell Signaling & 2983 \\
MTOR(Ser2448) & $11 / 53 / 39$ & Cell Signaling & 2971 \\
GSK3B & $12 / 53 / 39$ & Cell Signaling & 12456 \\
GSK3B(Ser9) & $12 / 53 / 39$ & Cell Signaling & 9336 \\
4E-BP1 & $12 / 53 / 39$ & Cell Signaling & 9452 \\
4E-BP1(Ser65) & $12 / 53 / 39$ & Cell Signaling & 9451 \\
RPS6 & $10 / 53 / 39$ & Cell Signaling & 2317 \\
RPS6(Ser235/236) & $10 / 53 / 39$ & Cell Signaling & 4858 \\
\hline
\end{tabular}

AKT1, AKT serine/threonine kinase 1; BECN1, Beclin1; FOXO1, forkhead box 01; FOXO3, forkhead box 03; GSK3B, glycogen synthase kinase 3 beta; LC $3 B$, microtubule-associated protein 1 light chain 3 beta; MTOR, mechanistic target of rapamycin; P62, sequestosome 1; RPS6, ribosomal protein S6; Ser, Serine; Tyr, tyrosine; ULK1, unc-51 like autophagy activating kinase 1; 4E-BP1, eukaryotic translation initiation factor $4 \mathrm{E}$ binding protein 1.

*Sample size (controls/nonsarcopenic COPD patients/sarcopenic COPD patients). 